\title{
Static Mechanical, Thermal Stability, and Interfacial Properties of Superheated Steam Treated Oil Palm Biomass Reinforced Polypropylene Biocomposite
}

\author{
Muhammad Nazmir Mohd Warid', Tengku Arisyah Tengku Yasim-Anuar', \\ Hidayah Ariffin ${ }^{1,2 *}$, Mohd Ali Hassan ${ }^{1}$, Yoshito Andou ${ }^{3}$ and Yoshihito Shirai ${ }^{3}$ \\ ${ }^{1}$ Department of Bioprocess Technology, Faculty of Biotechnology and Biomolecular Sciences, \\ 43400 UPM Serdang, Selangor, Malaysia \\ ${ }^{2}$ Laboratory of Biopolymer and Derivatives (BADs), Institute of Tropical Forestry and Forest Products \\ (INTROP), Universiti Putra Malaysia, 43400 UPM Serdang, Selangor, Malaysia \\ ${ }^{3}$ Department of Biological Functions and Engineering, Graduate School of Life Science and System Engineering, \\ Kyushu Institute of Technology, 2-4 Hibikino, Wakamatsu, Fukuoka 808-0196, Japan
}

\section{ABSTRACT}

In this study, three types of oil palm biomass (OPB) namely, oil palm mesocarp fiber (OPMF), oil palm empty fruit bunch (OPEFB) and oil palm frond (OPF), were studied and compared as the alternative fillers in the biocomposite reinforced polypropylene (PP). The fibers were treated using the optimal condition of superheated steam treatment obtained from previous study. The OPB/PP biocomposites at weight ratio of 30:70 were fabricated by melt blending technique and hot pressed moulding. Results showed that the tensile and flexural properties of optimized-SHS-treated OPB/PP biocomposites were improved by $9-30 \%$ and $9-12 \%$, respectively compared to the untreated OPB/PP biocomposites. The same observation was recorded for thermal stability. Improved surface morphology as shown by the tensile fracture surface indicates better interfacial adhesion between SHStreated OPB fibers with PP matrix during blending. Overall results showed that OPF/

ARTICLE INFO

Article history:

Received: 10 February 2020

Accepted: 13 November 2020

Published: 31 December 2020

DOI: https://doi.org/10.47836/pjst.28.S2.22

\section{E-mail addresses:}

nazmirwarid@gmail.com (Muhammad Nazmir Mohd Warid) tengkuarisyah@gmail.com (Tengku Arisyah Tengku Yasim-Anuar) hidayah@upm.edu.my (Hidayah Ariffin) alihas@upm.edu.my (Mohd Ali Hassan) yando@life.kyutech.ac.jp (Yoshito Andou) shirai@life.kyutech.ac.jp (Yoshihito Shirai)

* Corresponding author PP biocomposites had better properties compared to biocomposites prepared from OPMF and OPEFB, suggesting that OPF is a better OPB fiber choice as a filler in PP reinforced biocomposite.

Keywords: Biocomposite, oil palm mesocarp fiber (OPMF), oil palm empty fruit bunch (OPEFB), oil palm frond (OPF), superheated steam (SHS) treatment 


\section{INTRODUCTION}

Recently, research on the utilization of natural fibers over the synthetic fibers as the reinforcement in biocomposite has been extensively conducted due to the advantages of natural fibers. Natural fibers have low density, high toughness, good specific strength properties, good thermal and insulation properties, low in cost, non-abrasive to the processing equipment, biodegradable and easy to recycle (Acha et al., 2007; Akil et al., 2011; Bogoeva-Gaceva et al., 2007; Raju et al., 2008; Spoljaric et al., 2009). Several natural fibers have been tested for biocomposite fabrication such as kenaf, bamboo, baggase and rice husk. Due to the large amount of oil palm biomass (OPB) in Malaysia, the utilization of OPB to produce valuable products such as biocomposites has been studied (Karuppuchamy et al., 2015; Nordin et al., 2013; Then et al., 2013).

When using natural fiber as filler in polymer composite, surface modification is commonly needed due to incompatibility with the polymer matrix. Natural fiber consists of hydroxyl $(\mathrm{OH})$ group, causes it to be hydrophilic in nature, whereas polymer used in composite application is commonly hydrophobic. Such differences in wetting properties makes them difficult to achieve homogenous dispersion (Yasim-Anuar et al., 2020). Without surface modification, the resulting biocomposites may have poor mechanical properties, mainly due to poor stress transfer between both polymer matrix and fibers (Warid et al., 2016). There have been numerous methods used for surface modification of the natural fibers, including superheated steam (SHS) treatment (Nordin et al., 2013). Optimization study of SHS treatment on the oil palm biomass has been done in order to prepare suitable properties of fibers for biocomposite purpose (Warid et al., 2016). A previous study by Warid et al. (2016) revealed that SHS treatment was able to alter the fiber surface by removing hemicellulose and silica bodies, thus abled to enhance the fiber thermal stability and remove its moisture. This helps in enhancing compatibility with the polymer matrix.

This study aims to compare the use of several types of oil palm biomass, OPMF, OPEFB and OPF as reinforcement material in polypropylene biocomposite. The biocomposites produced were characterized for their mechanical, thermal stability, and surface morphological properties.

\section{MATERIALS AND METHODS}

\section{Raw Materials}

OPMF and OPEFB were obtained from Seri Ulu Langat Palm Oil Mill, Selangor, Malaysia while OPF was obtained from Taman Pertanian Universiti (TPU), Universiti Putra Malaysia (UPM). OPF was first shredded and pressed to remove the juice as described by Abdullah et al. (2015). The preparation of raw OPMF, OPEFB and OPF were conducted as described by Nordin et al. (2013). The size of each fiber was about $8-10 \mathrm{~cm}$ in length and no further mechanical treatment was done prior to SHS treatment. 


\section{Superheated Steam Treatment}

OPB fibers were treated using lab scale superheated steam oven (QF-5200C, Naomoto Corporation, Osaka, Japan) under ambient pressure as described by Nordin et al. (2013). Steam flow rate and heater power of SHS oven were kept constant at maximum value, 4.95 $\mathrm{kg} / \mathrm{h}$ and $6.6 \mathrm{~kW}$, respectively. OPB fibers were treated using optimized SHS treatment conditions which were obtained from the previous optimization studies (Warid et al., 2016). The optimized SHS treatment temperature and retention time for each OPB fibers are shown in Table 1.

Table 1

Optimized SHS treatment temperature and retention time for OPMF, OPEFB and OPF

\begin{tabular}{ccc}
\hline Fiber & Temperature $\left({ }^{\circ} \mathbf{C}\right)$ & Retention time (mins) \\
\hline OPMF & 265 & 5 \\
OPEFB & 280 & 5 \\
OPF & 300 & 9 \\
\hline
\end{tabular}

\section{Biocomposite Production}

Untreated and SHS-treated OPB fibers were then subjected to grinding using Wiley-type Mill to obtain the OPB powders. OPB powders which size is less than 150 um was chosen for the biocomposite production. The PP and OPB powders were dried in an oven at $60^{\circ} \mathrm{C}$ prior to use. The biocomposites were prepared by melt blending PP and fibers in a Brabender internal mixer (Germany) at $170^{\circ} \mathrm{C}$ with $50 \mathrm{rpm}$ rotor speed for 15 minutes. The weight ratio of $\mathrm{OPB} / \mathrm{PP}$ was fixed at 30:70. The PP pellet was first loaded in the mixer chamber for about 2 minutes to melt. Next, OPB fibers were added into the mixing chamber and mixing was continued for another 13 minutes. These compounded materials were then compressed into 1-3 mm thickness sheets with length of $150 \mathrm{~mm} \times 150 \mathrm{~mm}$ by a hydraulic hot-press at $170^{\circ} \mathrm{C}$ for 5 minutes, followed by cold pressing at $30^{\circ} \mathrm{C}$ for 5 minutes.

\section{Chemical Compositional Analysis}

Determination of lignin, cellulose and hemicellulose in the OPMF, OPEFB and OPF was done gravimetrically according to the method by (Iwamoto et al., 2008).

\section{Mechanical Test Analysis}

For tensile test, the test specimens were cut from $1 \mathrm{~mm}$ sample sheets using a dumbbell shape cutter of ATM D638 standard. A crosshead speed of $5 \mathrm{~mm} / \mathrm{min}$ was used, and the tests were performed at $25^{\circ} \mathrm{C}$. The results were expressed in terms of tensile strength, tensile modulus and elongation at break. The test was performed on five specimens for each formulation and the average values and standard deviations were reported. 
For flexural test, a three-point bending test was conducted on the biocomposites according to ASTM D790 standard. The test was conducted at $25^{\circ} \mathrm{C}$ with a crosshead speed of $1.3 \mathrm{~mm} / \mathrm{min}$ and a support span length of $48 \mathrm{~mm}$. The results were expressed in terms of flexural strength and flexural modulus.

\section{Thermogravimetric Analysis}

Thermogravimetric analysis (TGA) was conducted on a TG analyzer model TG4000 in order to confirm the change in the composition of untreated and SHS-treated OPB fibers. The OPB powder sample (6-8 mg) was placed on a ceramic pan. The sample was heated from $50-550^{\circ} \mathrm{C}$ at a heating rate of $10^{\circ} \mathrm{C} / \mathrm{min}$ under nitrogen flow of $100 \mathrm{~mL} / \mathrm{min}$.

\section{Surface Morphology Analysis}

The surface morphology of untreated and SHS-treated OPB fibers was observed under a scanning electron microscopy (SEM, LEO 1455 VPSEM Electron Microscopy Ltd., Cambridge, England). For SEM analysis, oven-dried samples were mounted in the stub and gold-coated for 180s prior to the SEM observation. The SEM micrographs were obtained with an acceleration voltage of $5 \mathrm{kV}$.

\section{RESULTS AND DISCUSSION}

\section{Chemical Composition of OPB fibers after SHS Treatment}

Based on Table 2, chemical composition analysis showed that the untreated OPMF contained lignin, hemicellulose and cellulose at 24, 35 and $40 \mathrm{wt} \%$, respectively. Lignin composition was higher for all of the OPB fibers after the SHS treatment, while cellulose and hemicellulose composition was reduced. It was reported that SHS treatment is an effective method for hemicellulose removal from lignocellulosic samples (Nordin et al., 2013). Meanwhile, it was demonstrated earlier that SHS treatment affected cellulose content due to thermal degradation of cellulose (Warid et al., 2016). Lignin composition was higher after SHS treatment as the result of cellulose and hemicellulose weight reduction. The

Table 2

Lignocellulose composition of OPB fibers after SHS treatment

\begin{tabular}{ccccc}
\hline & Fiber & $\begin{array}{c}\text { Lignin Content } \\
(\%)\end{array}$ & $\begin{array}{c}\text { Hemicellulose Content } \\
(\%)\end{array}$ & $\begin{array}{c}\text { Cellulose Content } \\
(\%)\end{array}$ \\
\hline \multirow{2}{*}{ OPMF } & Untreated & $24.41 \pm 3.01$ & $35.20 \pm 1.36$ & $40.39 \pm 1.74$ \\
& $265^{\circ} \mathrm{C} / 5$ mins & $50.40 \pm 1.21$ & $9.88 \pm 1.01$ & $39.71 \pm 0.20$ \\
OPEFB & Untreated & $14.53 \pm 2.23$ & $36.58 \pm 2.27$ & $48.89 \pm 4.50$ \\
& $280^{\circ} \mathrm{C} / 5$ mins & $40.49 \pm 3.65$ & $13.17 \pm 2.03$ & $46.34 \pm 5.67$ \\
OPF & Untreated & $14.84 \pm 1.21$ & $34.14 \pm 5.71$ & $51.02 \pm 4.72$ \\
& $300^{\circ} \mathrm{C} / 9 \mathrm{mins}$ & $40.49 \pm 0.13$ & $9.62 \pm 3.29$ & $49.89 \pm 3.42$ \\
\hline
\end{tabular}


complexity of lignin structure makes it difficult to be degraded, apart from having wide range of thermal degradation temperature which is from 190 to $900^{\circ} \mathrm{C}$. This explains the increased in lignin composition after SHS treatment.

\section{Mechanical Properties of OPB Biocomposites}

Tensile Properties of Biocomposites. The effectiveness of SHS-treated OPB fibers as reinforcement material in biocomposites can be determined by comparing mechanical properties of SHS-treated OPB/PP biocomposites and untreated OPB/PP biocomposites. Figure 1 shows the tensile strength (TS) and tensile modulus (TM) of both untreated and SHS-treated OPB/PP biocomposites, and PP was used as the control. The TS and TM of $\mathrm{PP}$ composites were reported to be about $40 \mathrm{Mpa}$ and $7532 \mathrm{MPa}$, respectively. In general, the addition of OPB fibers (treated and untreated) into the PP composite reduced the TS. TS is the measurement of the force required to pull material to the point where it breaks. In other words, TS of a material is the maximum amount of stress that it can take before failure, for example in this case, breaking into two. TS of OPB/PP biocomposites reduced

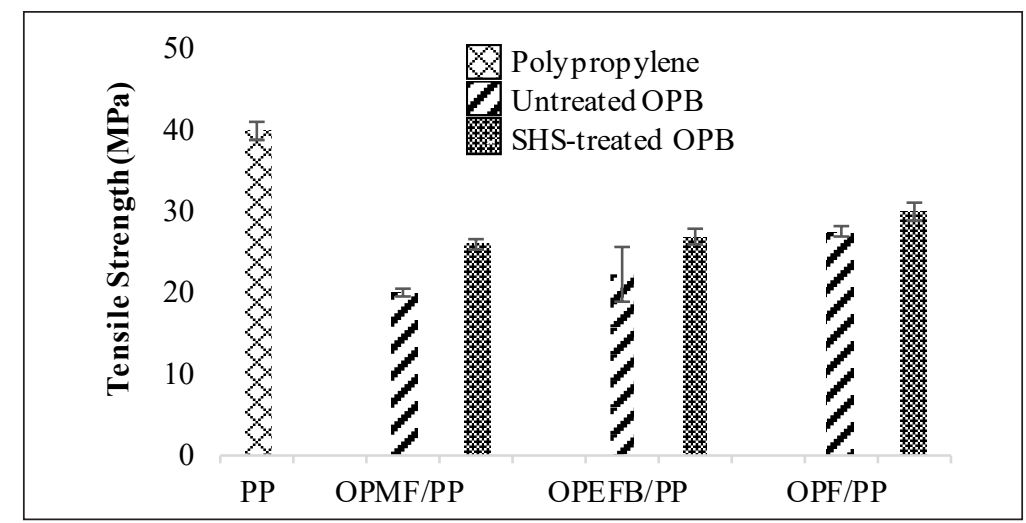

(a)

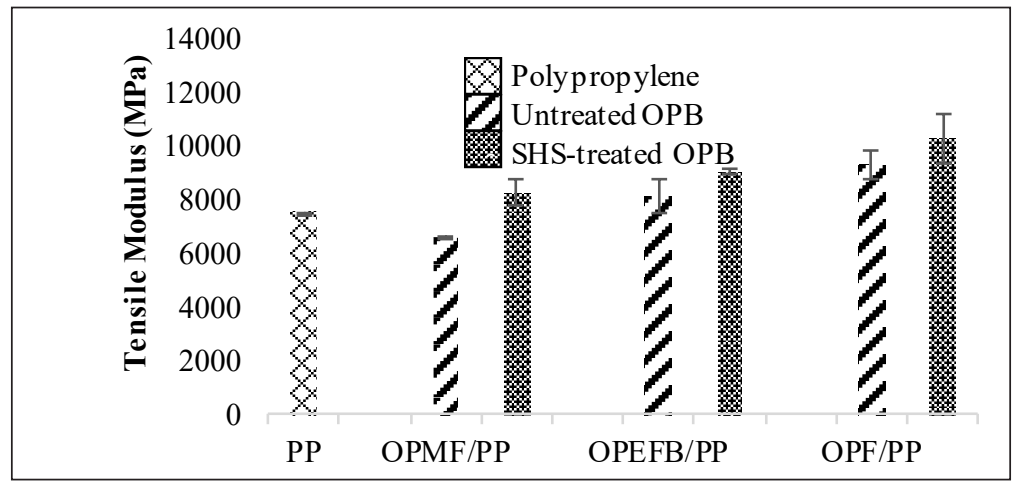

(b)

Figure 1. (a) Tensile strength (MPa) and (b) Tensile modulus (MPa) of OPB biocomposites 
as low as 50\% compared to TS of PP composite due to poor interfacial adhesion between hydrophobic PP and hydrophilic OPB fibers. This is due to the disruption in structural integrity of PP by the introduction of the fibers (Norrrahim, 2018).

It is interesting to note that $\mathrm{TM}$ of the $\mathrm{OPB} / \mathrm{PP}$ biocomposites were higher compared to that of neat PP, for both untreated and SHS-treated OPB. TM can be explained as the ratio of the pressure on the material (stress) to the strain of the material. In other words, it measures the stiffness of the material. Since fibers are usually stiffer compared to polymer, the addition of OPB fibers into the PP composite caused an increment in TM.

The effect of SHS treatment can be seen in all OPB fiber samples whereby the TS and TM values for all samples were increased when SHS-treated OPB was used as compared to untreated OPB. This can be explained by the improvement in hydrophobicity of the SHStreated OPB fibers as a result of hemicellulose removal, which contributed to improved compatibility and interfacial adhesion between SHS-treated OPB fibers and PP. Apart from that, SHS treatment improved the adhesive characteristics of OPB fibers by removing impurities covering the surface of the fiber, resulted in fibers with relatively clean and rough surface which are favourable for fibers-polymer interaction (Nordin et al., 2017). All of these reasons contributed to the increase in both TS and TM of SHS-treated OPB/ PP biocomposites compared to untreated OPB/PP biocomposites.

OPF/PP biocomposites showed the highest TS and TM at $29.8 \mathrm{MPa}$ and $10303 \mathrm{MPa}$, respectively. This was followed by OPEFB/PP biocomposites with TS and TM of 26.8 $\mathrm{MPa}$ and $9050 \mathrm{MPa}$, respectively, and finally OPMF/PP biocomposites (TS of $26 \mathrm{MPa}$ and $\mathrm{TM}$ of $8273 \mathrm{MPa}$ ). The difference in cellulose composition after SHS treatment (Table 1) is expected to be the main reason which contributed to this observation. SHS-treated OPF which contained the highest cellulose showed the best mechanical properties compared to OPEFB and OPF. It is well-known that cellulose contains crystalline portion which provides strength to the biocomposite, and hence the results obtained. Based on this, it can be suggested that OPF is a superior OPB to be used as filler to improve the mechanical properties of PP biocomposite, as compared to OPMF and OPEFB.

Flexural Properties of Biocomposites. Figure 2 shows the flexural strength (FS) and flexural modulus (FM) of both untreated and SHS-treated OPB/PP biocomposites. Neat PP which was used as benchmarked sample had FS and FM of $47 \mathrm{MPa}$ and $1524 \mathrm{MPa}$, respectively. Overall, all OPB/PP biocomposite samples had lower FS, but higher FM compared to neat PP. In all cases, SHS-treated OPB/PP had higher FS and FM values compared to untreated OPB/PP. This can be explained by better compatibility of SHStreated OPB with PP as compared to untreated OPB, due to the removal of hemicellulose which caused partial removal of hydrophilic component. This ultimately improved interfacial adhesion between SHS-treated OPB fibers and PP matrix which in turn produced 


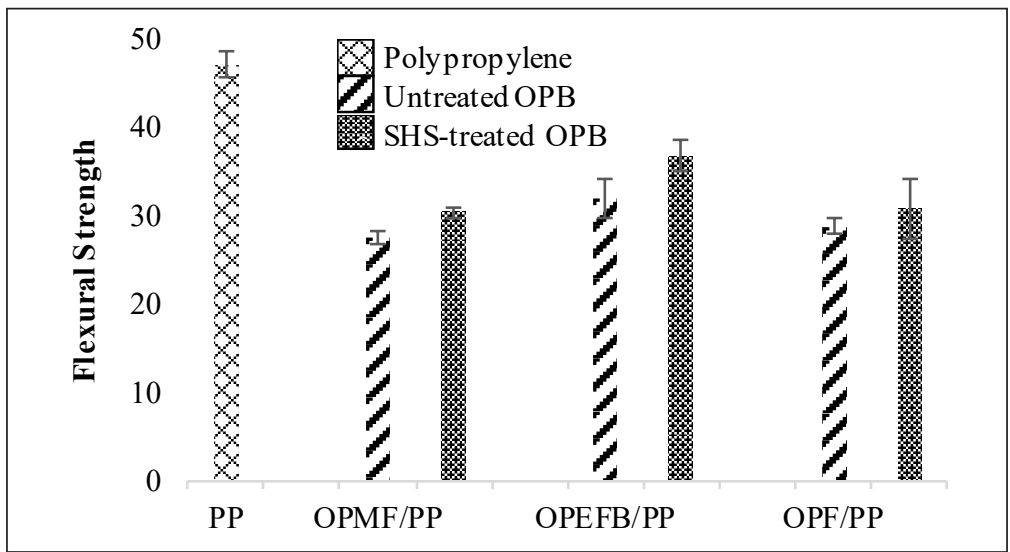

(a)

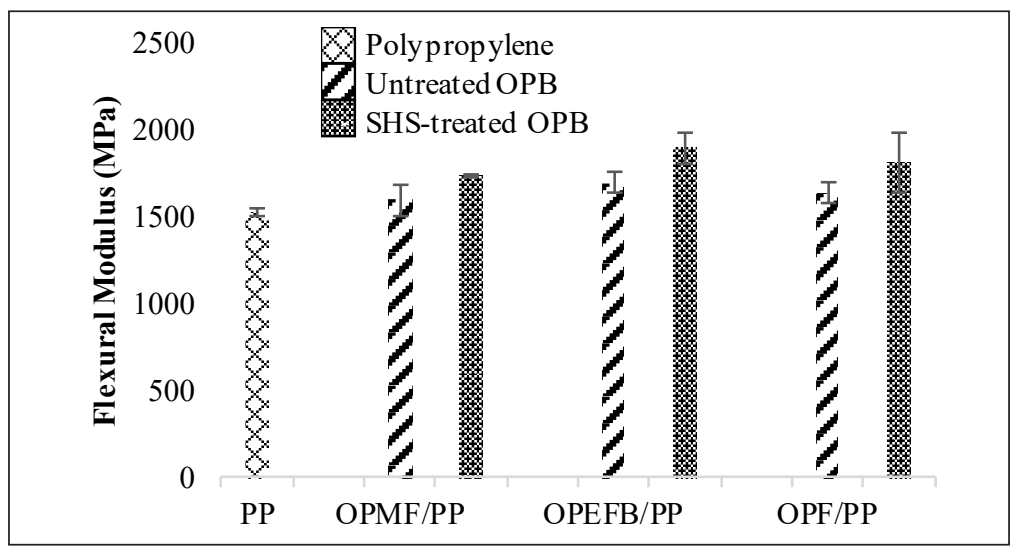

(b)

Figure 2. (a) Flexural strength (MPa) and (b) Flexural modulus (MPa) of OPB biocomposites.

biocomposite with better bending and crack propagation resistance (Nordin et al., 2017). On the other hand, segmental movement of the polymer chains can be hindered when natural fibers are introduced into the polymer matrix and this caused the biocomposites to become stiffer and eventually improved the FM as compared to neat PP.

Thermal Stability of Biocomposites. The thermal stability of biocomposites was evaluated via thermogravimetric (TG) analysis. TG thermograms of $\mathrm{PP}$ and $\mathrm{OPB} / \mathrm{PP}$ biocomposites are illustrated in Figure 3. The information of degradation temperature at 10 and $50 \%$ weight loss, temperature at maximum rate degradation, percentage of weight loss and percentage of residual left at $500^{\circ} \mathrm{C}$ can be interpreted from the thermograms. Detailed interpretations are tabulated in Tables 3.

Degradation temperature at $\mathrm{T}_{10 \%}$ was used to determine the thermal stability of the biocomposites. It is seen from Figure 3 and Table 3, thermal stability of the SHStreated $\mathrm{OPB} / \mathrm{PP}$ biocomposites were higher in comparison with the untreated $\mathrm{OPB} / \mathrm{PP}$ 
biocomposites. The removal of hemicellulose, which possesses the lowest degradation temperature among other lignocellulosic components have increased the thermal stability of the SHS-treated fibers and eventually increased the thermal stability of the biocomposites (Nordin et al., 2017).

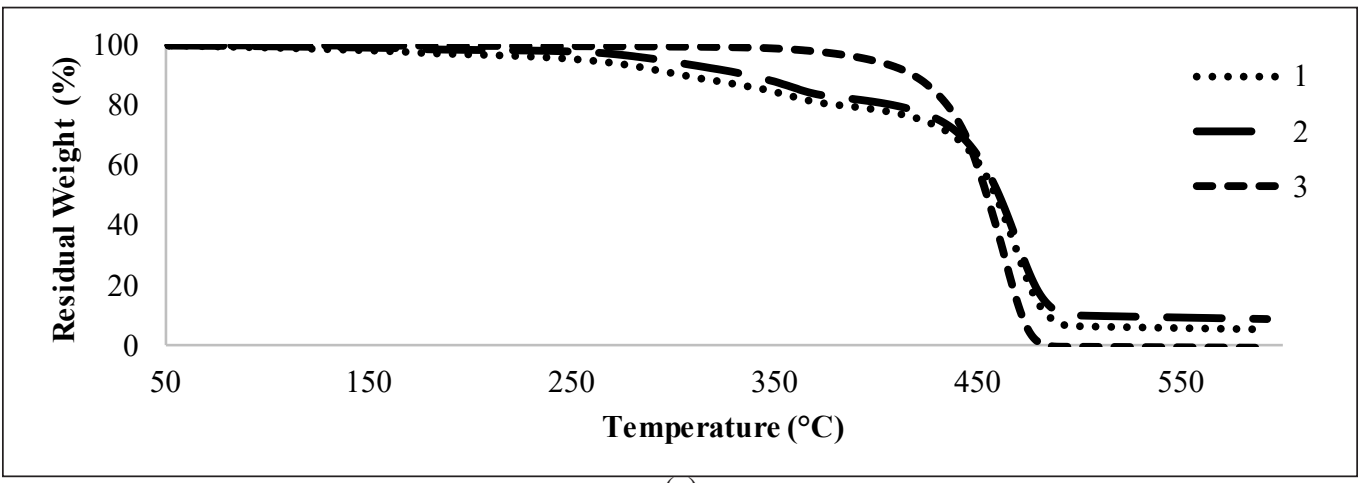

(a)

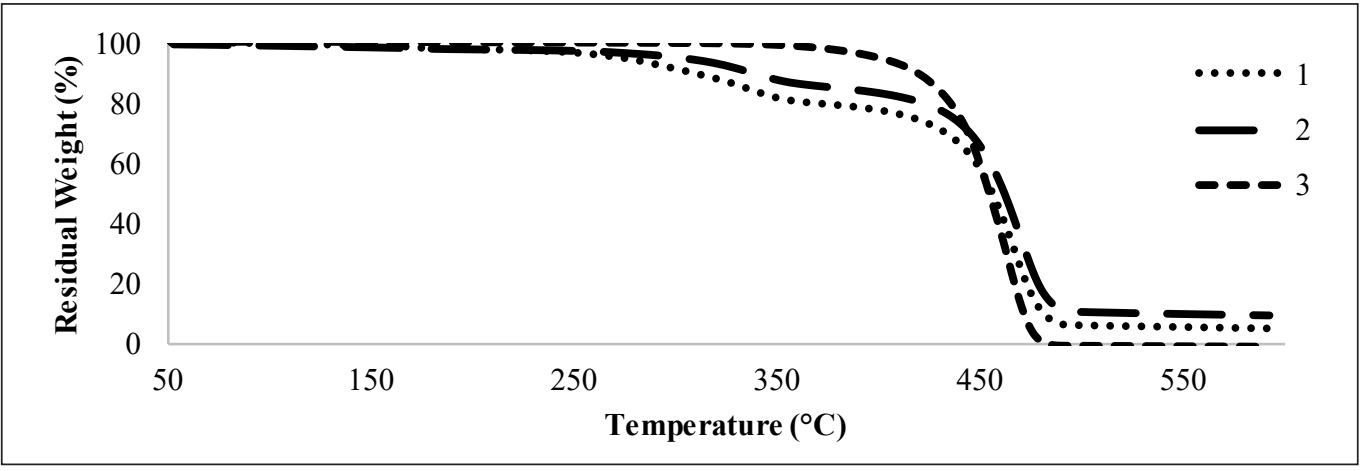

(b)

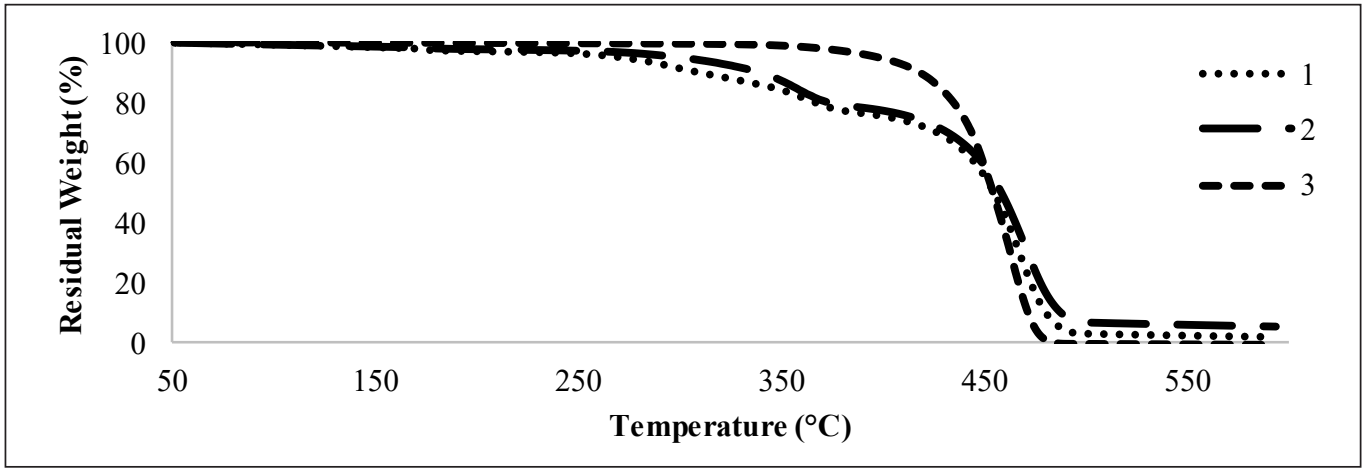

(c)

Figure 3. TG thermogram of (a) OPMF biocomposite, (b) OPEFB biocomposite and (c) OPF biocomposite. Untreated OPB is labelled as (1), SHS-treated OPB (2) and Polypropylene (3) 
Table 3

Thermal degradation temperature at 10\% fiber degradation as shown by TG thermogram

\begin{tabular}{cccc}
\hline \multicolumn{2}{c}{ Biocomposite } & Degradation temperature $\left({ }^{\circ} \mathbf{C}\right), \boldsymbol{T}_{\boldsymbol{1 0}}$ & Residual weight at $\mathbf{5 0 0}^{\circ} \mathbf{C}(\mathbf{\%})$ \\
\hline \multirow{2}{*}{ OPMF } & Untreated & 305 & 6.1 \\
& Treated & 337 & 9.9 \\
\multirow{3}{*}{ OPEFB } & Untreated & 307 & 6.3 \\
& Treated & 339 & 10.3 \\
\multirow{2}{*}{ OPF } & Untreated & 302 & 3.5 \\
& Treated & 339 & 6.6 \\
\hline
\end{tabular}

Residual weight at $500^{\circ} \mathrm{C}$ can be related to the char formation of the biocomposites which is directly correlated to the potency of flame retardation. SHS-treated-OPEFB/PP biocomposite has the highest residue content, which is $10.3 \%$, followed by SHS-treated OPMF/PP biocompsite (9.9\%) and SHS-treated OPMF/PP biocompsite (6.6\%).

Surface Morphology of Biocomposites. The tensile fractured surface of untreated and SHS-treated OPB/PP biocomposites were analyzed using a scanning electron microscope in order to determine the adhesion behaviour between untreated and SHS-treated OPB fibers with PP matrix. Figure 4 shows the scanning electron micrographs of tensile fractured surfaces of untreated and SHS-treated OPB/PP biocomposites. These tensile fractured surface micrographs can provide useful information regarding the failure mechanism under tensile load for the corresponding biocomposites.

The SEM micrographs of untreated OPB/PP biocomposites clearly show the gaps on the OPB/PP caused by the de-bonding of fibers from polymer matrix during the tensile test. Apart from that, cavities are also observed which can be explained by the fiber pull-out during tensile test. This may be attributed by the poor interfacial adhesion due to incompatibility between hydrophilic OPB fibers and hydrophobic PP matrix. The incompatibility can also be represented by the heterogenous structure where OPB fibers and PP matrix can be easily distinguished in the micrographs. Poor interfacial adhesion eventually resulted in the premature failure as a result of poor stress transfer across the fiber-matrix interface (Nordin et al., 2013b; Warid et al., 2016; Yasim-Anuar et al., 2019). Hence, this explains the decrease in tensile and flexural strength of the biocomposites.

On the other hand, SHS-treated OPB/PP biocomposites exhibited better compatibility as shown by the scarcuty or absence of gaps and cavities on the SHS-treated OPB/PP interface region. The removal of hemicellulose during SHS treatment of OPB fibers had improved the hydrophobicity of the fibers which then enhanced the interaction with the hydrophobic PP matrix. SHS treatment also caused the removal of silica and waxy layers from the surface of OPB fibers (Nordin et al., 2013) which provided rougher surface of fibers which can be exploited by the PP matrix for a better mechanical interlocking during biocomposite fabrication and subsequently reduced the number of fiber pull-out during tensile test. 


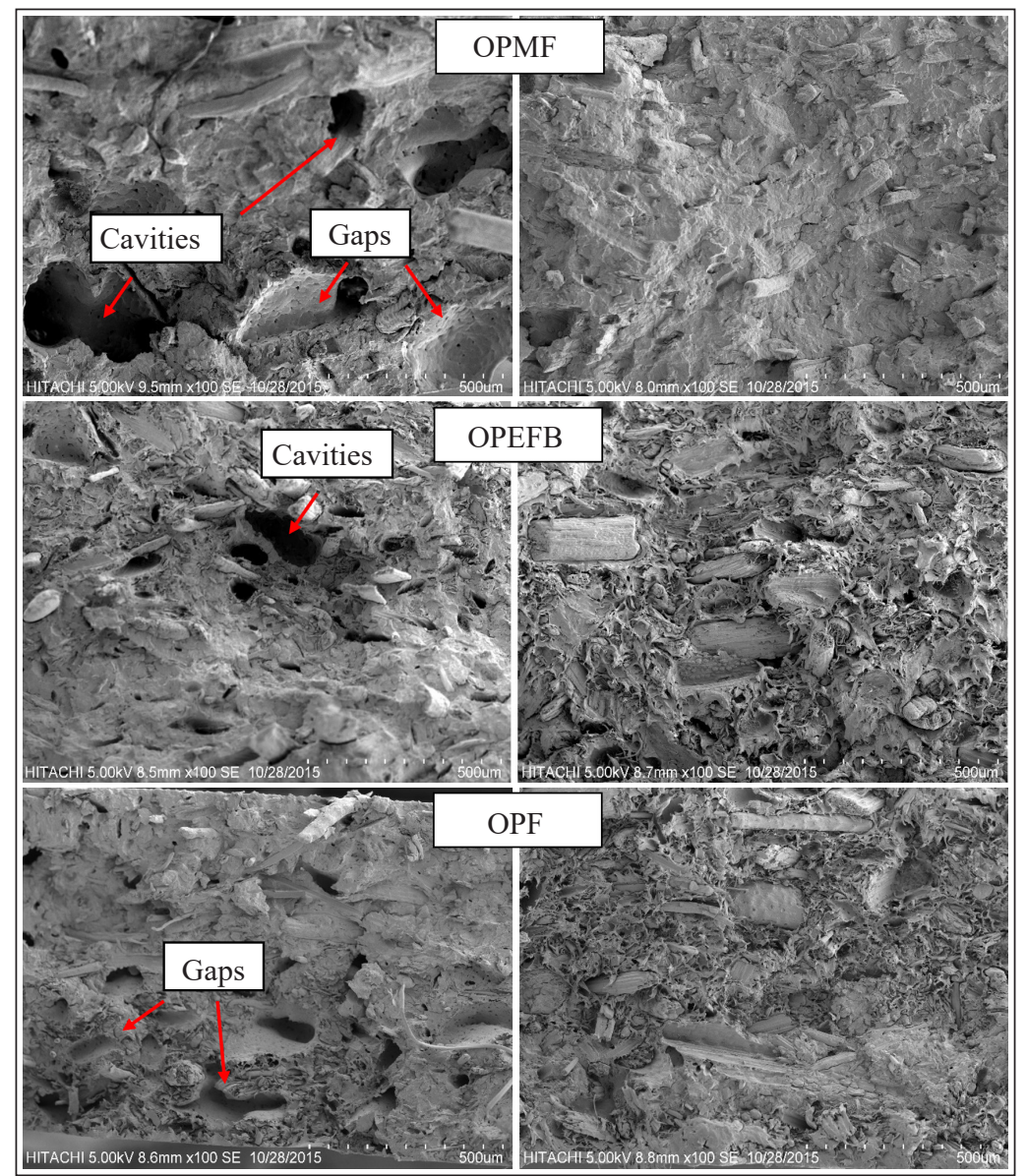

Figure 4. SEM micrographs of tensile fractured surface of untreated (L) and SHS-treated (R) OPB/PP biocomposites

\section{CONCLUSIONS}

The properties of the OPB/biocomposites were greatly affected by the types of oil palm biomass used, as well as the treatment of the fiber by SHS. Overall, OPF exhibited better performance in term of mechanical properties. This is contributed by the higher cellulose content in the OPF, the highly crystalline component in lignocellulose which could improve the mechanical properties of the biocomposites prepared using OPF as the filler. On the other hand, SHS treatment greatly affected both the mechanical and thermal properties of the SHS-treated OPB biocomposites as compared to the untreated OPB biocomposites. The removal of hemicellulose during SHS treatment improved the compatibility of the OPB with PP, contributing to better mechanical properties. The removal of hemicellulose also improved the thermal stability of the biocomposites as hemicellulose is the least thermally stable component in lignocellulose. 


\section{ACKNOWLEDGEMENT}

The authors would like to acknowledge the Ministry of Higher Education, Malaysia, and Universiti Putra Malaysia (UPM), for the financial support. The authors also would like to thank Forest Research Institute Malaysia (FRIM) for the technical support throughout the experiments and to Taman Pertanian Universiti (TPU) UPM and Seri Ulu Langat Palm Oil Mill, Selangor for the raw material supply.

\section{REFERENCES}

Abdullah, S. S. S., Shirai, Y., Bahrin, E. K., \& Hassan, M. A. (2015). Fresh oil palm frond juice as a renewable, non-food, non-cellulosic and complete medium for direct bioethanol production. Industrial Crops and Products 63, 357-361. doi:10.1016/j.indcrop.2014.10.006

Acha, B. A., Reboredo, M. M., \& Marcovich, N. E. (2007). Creep and dynamic mechanical behavior of PP-jute composites: Effect of the interfacial adhesion. Composites Part A: Applied Science and Manufacturing, 38(6), 1507-1516. doi:10.1016/j.compositesa.2007.01.003

Akil, H., Omar, M. F., Mazuki, A. A. M., Safiee, S. Z. A. M., Ishak, Z. M., \& Bakar, A. A. (2011). Kenaf fiber reinforced composites: A review. Materials \& Design, 32(8-9), 4107-4121. doi:10.1016/j. matdes.2011.04.008

Bogoeva-Gaceva, G., Avella, M., Malinconico, M., Buzarovska, A., Grozdanov, A., Gentile, G., \& Errico, M. E. (2007). Natural fiber eco-composites. Polymer Composites, 28(1), 98 - 107. doi:10.1002/pc.20270

Karuppuchamy, S., Andou, Y., Nishida, H., Nordin, N. I. A. A., Ariffin, H., Hassan, M. A., \& Shirai, Y. (2015). Superheated steam treated oil palm frond fibers and their application in plastic composites. Advanced Science, Engineering and Medicine, 7(2), 120-125. doi:10.1166/asem.2015.1659

Nordin, N. I. A. A., Ariffin, H., Hassan, M. A., Shirai, Y., Ando, Y., Ibrahim, N. A., \& Yunus, W. M. Z. W. (2017). Superheated steam treatment of oil palm mesocarp fiber improved the properties of fiber-polypropylene biocomposite. BioResources, 12(1), 68-81. doi:10.15376/biores.12.1.68-81

Nordin, N. I. A. A., Ariffin, H., Andou, Y., Hassan, M. A., Shirai, Y., Nishida, H., \& Ibrahim, N. A. (2013). Modification of oil palm mesocarp fiber characteristics using superheated steam treatment. Molecules, 18(8), 9132-9146. doi:10.3390/molecules 18089132

Norrrahim, M. N. F. (2018) Superheated steam pretreatment of oil palm biomass for improving nanofibrillation of cellulose and performance of polypropylene / cellulose nanofiber composites. (Doctoral thesis) Universiti Putra Malaysia, Malaysia.

Raju, C., Ratnam, C. T., Ibrahim, N. A., Rahman, M. Z. A., \& Yunus, W. M. Z. W. (2008). Enhancement of PVC/ENR blend properties by poly (methyl acrylate) grafted oil palm empty fruit bunch fiber. Journal of Applied Polymer Science, 110(1), 368-375. doi:10.1002/app.28662

Spoljaric, S., Genovese, A., \& Shanks, R. A. (2009). Polypropylene-microcrystalline cellulose composites with enhanced compatibility and properties. Composites Part A: Applied Science and Manufacturing, 40(6-7), 791-799. doi:10.1016/j.compositesa.2009.03.011 
Then, Y. Y., Ibrahim, N. A., Zainuddin, N., Ariffin, H., \& Yunus, W. M. Z. W (2013). Oil palm mesocarp fiber as new lignocellulosic material for fabrication of polymer/fiber biocomposites. International Journal of Polymer Science, 2013, 1-7. doi:10.1155/2013/797452

Warid, M. N. M., Ariffin, H., Hassan, M. A., \& Shirai, Y. (2016). Optimization of superheated steam treatment to improve surface modification of oil palm biomass fiber. BioResources, 11(3), 5780-5796. doi:10.15376/ biores.11.3.5780-5796

Yasim-Anuar, T. A. T., Ariffin, H., Norrrahim, M. N. F., Hassan, M. A., Andou, Y., Tsukegi, T., \& Nishida, H. (2020). Well-dispersed cellulose nanofiber in low density polyethylene nanocomposite by liquid-assisted extrusion. Polymers, 12(4), 1-17. doi:10.3390/polym12040927

Yasim-Anuar, T. A. T., Ariffin, H., Norrrahim, M. N. F., Hassan, M. A., Tsukegi, T., \& Nishida, H. (2019). Sustainable one-pot process for the production of cellulose nanofiber and polyethylene/cellulose nanofiber composites. Journal of Cleaner Production, 207, 590-599. doi:10.1016/j.jclepro.2018.09.266 